\title{
REVIEW
}

\section{The impact of nitrogen starvation on the dynamics of lipid and biomass production in Scenedesmus sp.}

\author{
Gamze Dogdu Okcu ${ }^{1, *}$ \\ ${ }^{1}$ Bolu Abant Izzet Baysal University, Environ. Eng. Dept., Golkoy Campus, 14030 Bolu, TURKEY
}

\begin{abstract}
Microalgal lipid is a major natural feedstock for biodiesel production. However, microalgae-based biofuel technology comes with obstacles to production, such as high investment and operating costs. To overcome these problems, nowadays some strategies have been used during cultivation stage of the microalgae for enhancing biomass and accumulate lipids and carbohydrates which could be used for biofuel production. The most common methods applied to microalgae are classified as nutrient stress and changes in growth conditions that lead to increase the lipid content in the species without decreasing the growth rate of their potential strains or by simultaneously increasing both of these. Scenedesmus sp. are considered to be the most appropriate microalgae to culture commercially due to their high biomass, lipid and carbohydrate yield. The purpose of this review was to describe nutrient stress strategy to develop biofuels as a sustainable alternative to fossil fuels and, in particular, with respect to nitrogen nutrient limitations, the lipid yield and biomass development in Scenedesmus sp. microalgae. The nitrogen starvation/limitation strategy that will increase the general economic feasibility of microalgal lipid production and affect the fatty acid composition was presented.
\end{abstract}

Keywords: Biofuel, lipid productivity, microalgae, nitrogen starvation, Scenedesmus sp., triacylglycerol (TAG)

\section{INTRODUCTION}

Biofuels have been considered to be a clean alternative to fossil fuels in recent years because of their sustainability, nontoxicity, biodegradability, and low greenhouse gas emissions [1-3]. Microalgae have a 30\% lipid content, which is higher than that in either palm oil or soybean oil, which are currently used in biodiesel production $(<5 \%$ of dry biomass) $[4,5]$. The lipid content in microalgae varies from 20 to $40 \%$ on a dry-weight basis; whereas, some microalgae have lipid contents as high as 85\% [6, 7]. Microalgae offer many advantages over traditional oil crop biofuels and chemicals of high value because of their properties of high lipid productivity and photosynthetic efficiency, robust environmental adaptation, failure to compete with nutrients or arable lands, rapid fixation of environmental carbon, and ease of cultivation in media similar to wastewater and other media [8]; however, the biggest obstacle to obtaining biofuels from algae is the high cost of biodiesel production from oleaginous microalgae and the need for and cost of pilot-scale studies $[9,10]$. Optimizing the conditions under which microalgae strains can be cultivated is crucial to creating enough lipid production to enable biofuel production on an economically significant scale [11]. Stimulating stress responses by limiting nutrients and controlling cultivation is one of the methods by which the lipid content in microalgae can be improved [12-14].

Microalgae are rich in tri- and diglycerides, phosphoand glycolipids, hydrocarbons, and other lipids [6], [15]. Under suitable environmental conditions, microalgae synthesize fatty acids to produce membrane glycerolipids, mainly glycolipids and phospholipids; however, several microalgae alter their lipid biosynthetic pathways to produce a large amount of neutral lipids in the form of triglycerides (TAGs), stored mostly in cytosolic lipid bodies under stress conditions [16]. Under these conditions, microalgae cell division will stop, and TAGs will be stored in their cells as a survival approach to withstand these adverse conditions [17]. These TAGs, which are generally found in a cell as storage lipids,

Corresponding Author: gamzedogdu@ibu.edu.tr(Gamze Dogdu Okcu)

Received 14 April 2019; Received in revised form 18 July 2019; Accepted 29 July 2019

Available Online September 2019

Doi: https://doi.org/10.35208/ert.553536

(C) Yildiz Technical University, Environmental Engineering Department. All rights reserved. 
can be converted into biodiesel [18]. Lipids are stored in microalgae cells when accessible nutrients are consumed and depleted from a culture medium and become growth-limiting factors [19]. In addition, the amount and type of lipids are different in different species; therefore, the growth and cultivation conditions of the microalgae species are altered to affect their fatty acids [20]. Scenedesmus sp. is considered to be one of the most important microalgae for producing biofuel raw material because of their high biomass, high lipid and carbohydrate content, and ability to grow under various wastewater conditions [21].

Fatty acid ratios and lipid contents in microalgae differ according to environmental and cultural parameters, such as nitrogen and phosphorus concentrations, light intensity, growth phase, lightreceiving period, temperature, salinity, and carbon dioxide $\left(\mathrm{CO}_{2}\right)$ concentration $[22,23]$. Among these, nitrogen starvation is the most important technique reported in the literature that increases microalgae biomass and biochemical components, such as lipids and carbohydrates [24]. The purpose of this review was to investigate biomass productivity in the Scenedesmus sp., a species with a high lipid content, to enable improvement of the economic feasibility of microalgae-based biofuels and to examine the methods by which nitrogen starvation or limitation increase the lipid yield and carbohydrate production; and also to guide researchers in understanding the reaction of Scenedesmus sp. against its cultivation in nitrogen-limited nutrient media.

\section{MICROALGAE CULTURE CONDITIONS}

The growth characteristics and composition of microalgae depend largely on four fundamental cultivation conditions-photoautotrophic, heterotrophic, mixotrophic, and photoheterotrophic [25]-[26]. Table 1 provides the characteristics of these different conditions.

Table 1. Characteristics of the different microalgae culture conditions [27]

\begin{tabular}{ccc}
\hline Culture conditions & Energy source & Carbon source \\
\hline Photoautotrophy & Light & Inorganic \\
Heterotrophy & Organic carbon & Organic \\
Photoheterotrophy & Light & Organic \\
Mixotrophy & Light and organic carbon & Inorganic and organic \\
\hline
\end{tabular}

Microalgae are divided into two groups-autotrophic and heterotrophic. Autotrophic microalgae use sunlight to convert $\mathrm{CO}_{2}$ into lipids without the need for carbon; however, cultivation requires a large area, and lipid accumulation is slow [28]. On the contrary, heterotrophic microalgae have a high lipid content and rapid growth rate and lipid accumulation; therefore, they have a high capacity for lipid production. Photoautotrophic cultivation, in which microalgae utilize inorganic carbon (such as $\mathrm{CO}_{2}$ ) and solar energy to generate chemical energy, is the most widespread technique [29]. In heterotrophic cultivation, microalgae can grow in the absence of light by utilizing glucose and other similar organic carbon sources [30]. Although the heterotrophic system provides higher lipid output than the autotrophic system, the need for organic substrates and their cost prevent its industrial-scale production and commercialization [31].

Mixotrophic cultivation combines both autotrophic and heterotrophic systems because both $\mathrm{CO}_{2}$ and organic carbon are simultaneously absorbed [32]. In photoheterotrophic cultivation, microalgae need both organic carbon and light. The difference between the two is that photoheterotrophs use light and mixotrophs use organic carbon as an energy source.

When comparing different microalgae species with different carbon sources, autotrophs generally have satisfactory lipid content, but because their growth rate is low, subsequent lipid production efficiency is also low. The opposite is true for heterotrophs, in which lipid content is low but the growth rate is very high, resulting in higher biomass and lipid production. Mixotrophs utilize both inorganic and organic carbon sources; these conditions result in the highest biomass and lipid yield among all cultivation methods [14].

\section{MICROALGAL LIPID CLASSIFICATION AND ACCUMULATION STRATEGIES}

Microalgae-based biodiesel technologies contain the conditions that determine optimum microalgae growth, define economically feasible and efficient culturing media, harvest and separate microalgae biomass, and produce biodiesel (Fig 1). Biodiesel production from microalgae comprise the following four basic steps: isolating and characterizing the microalgae, producing microalgae biomass, harvesting, and processing [33].

Lipids are not only the energy sources in microalgae cells but also a promising raw material for biodiesel production [37]. When energy input (photosynthesis rate) exceeds energy output (cell growth and division), microalgae synthesize lipids [38]. These microalgae contain refined lipids that can be extracted to create fuel oils [39]. There are more than 300,000 known microalgae species, of which $70 \%$ have a high lipid content and a fuel yield of 9500-35000 liters per $1000 \mathrm{~m}^{2}$ [40]. Microalgae have advantages over other microorganisms in biofuel production because of their greater biomass productivity and ability to accumulate high amounts of lipids [42]. 


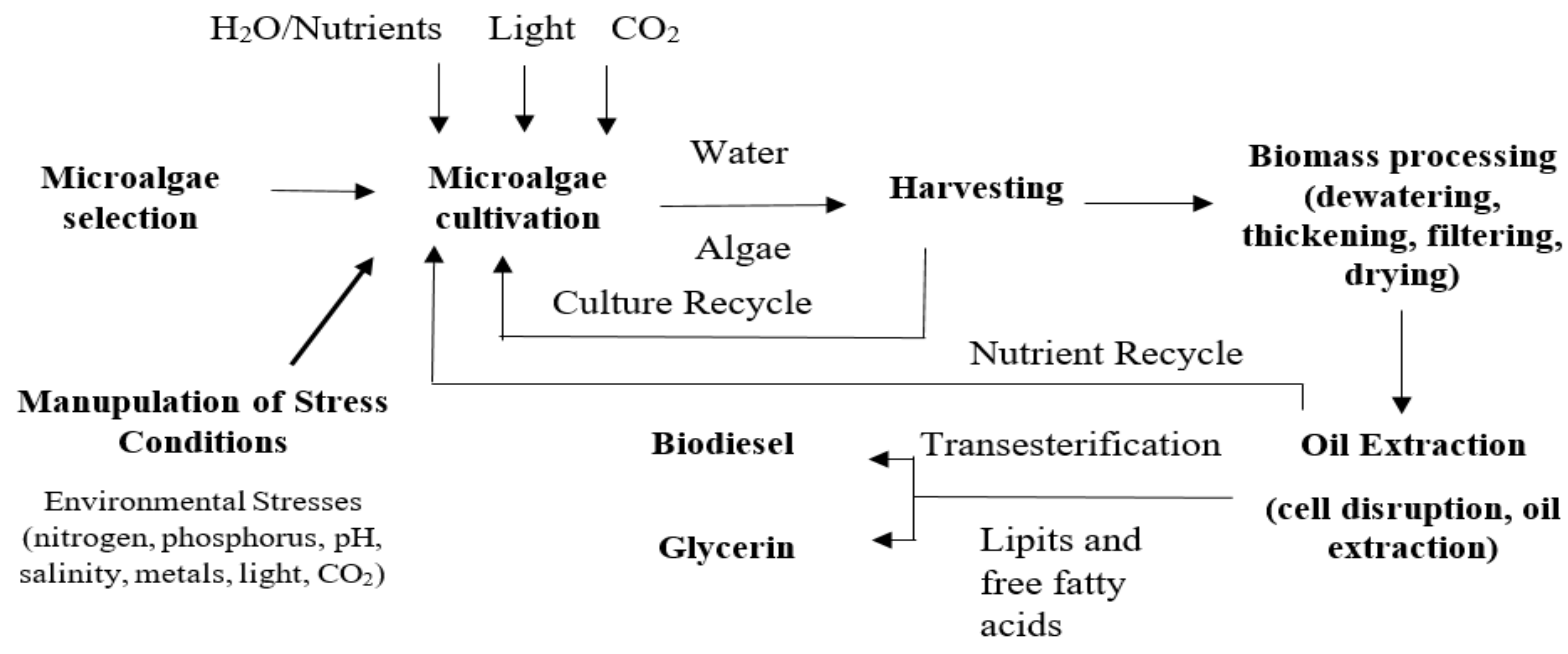

Fig 1. Overall process of biodiesel production from microalgae [34-36]

The biochemical composition of microalgae comprises four main components-proteins, carbohydrates, nucleic acids in varying ratios among species, and lipids. Lipids are the highest energy source at $37.6 \mathrm{~kJ}$ $\mathrm{g}-1$, which can be either polar or nonpolar, followed by proteins at $16.7 \mathrm{~kJ} \mathrm{g-1}$ and carbohydrates at $15.7 \mathrm{~kJ}$ $\mathrm{g}-1$. Depending on the metabolic rate, the ratio of these lipids changes during different microalgae growth periods [43]. Neutral lipids are composed of glycerol and free fatty acids (FFAs) and because of their low degree of unsaturation, they are more suited for producing biodiesel [44]. Polar lipids, such as phospholipids (PL) and glycolipids (GL), are structural [45] and are important components of the outer

Table 2. Lipid classifications in microalgae [49] membranes of chloroplasts. Nonpolar (neutral) lipids, such as TAGs, diglycerides (DAGs), monoglycerides (MAGs), FFAs, pigments (e.g., chlorophylls), and hydrocarbons, are stored. Algae store lipids differently depending on the species, their growth periods, and environmental conditions. FFA components also vary with different microalgae strains. In most cases, polyunsaturated fatty acids (PUFAs) are located in the structural lipids, while monounsaturated fatty acids (MUFAs) and saturated fatty acids (SFAs) are located in the stored lipids [46][48]. Table 2 presents the lipid classifications in microalgae.

\begin{tabular}{ccc}
\hline & & Polar Lipids \\
Neutral Lipids & Glycolipids & Phospholipids \\
\hline Triglycerides & Phosphatidylcholine & Polymerized triglyceride \\
Wax esters & Phosphatidylethanolamine & Monogalactosyl diglyceride \\
Hydrocarbons & Phosphatidylserine & Digalactosyl diglyceride \\
Free fatty acids & Phosphatidylglycerol & \\
Sterols & Phosphatidylinositol & \\
\hline
\end{tabular}

Algae growth has five different phases [50] as follows: 1) lag or acclimation, 2) logarithmic, 3) decreasing, 4) stationary, and 5) death. To obtain the highest biomass yield, the growth rate in the media should always be within the logarithmic growth phase. The highest lipid synthesis takes place during the transition between the lag and the stationary growth phases (i.e., stages 2 and 3) [51].

Microalgae harvested during the stationary phase have less polar lipids and more neutral lipids (e.g., TAGs) than those harvested during the logarithmic growth phase, so harvesting at the stationary phase is more suitable for biodiesel production [47].
The most well-known lipids are TAGs formed by one glycerol and three fatty acids, and PLs (and GLs), formed by two fatty acids and one phosphate (and carbohydrate). The natural lipids produced by microalgae are TAGs, which makes them the main focal point because of having the necessary molecular structure for biodiesel production [52]. TAG molecules function as electron pools when the electron supply of energy and carbon storage compounds and photosynthesis cannot meet the demand of growing cells [47]. The common methyl esters used in biodiesels are methyl palmitate (C16:0), methyl stearate (C18:0), methyl oleate (C18:1), methyl linoleate (C18:2), and methyl linolenate (C18:3). In other words, microalgae lipids are 
generally composed of neutral lipids with a lower amount of unsaturation [43], which is the natural fatty acid profile of microalgae [53]. The optimum fatty acid ratio from microalgae for producing biodiesel is $5: 4: 1$ for C16:1, C18:1, and C18:2, respectively, which gives biodiesel its distinguishing properties, such as high cetane number (CN), low iodine value (IV), and low cold filter plugging point (CFPP) [11].
The reaction of fatty acids in 1 mole of triglycerides and 3 moles of alcohol during biodiesel production yields fatty acid methyl esters (FAME) and glycerol (side product) (Fig 2). The glycerol can be separated from the biodiesel using phase separation techniques or "transesterification", in which glycerol is displaced by methanol in the presence of a catalyst [6].

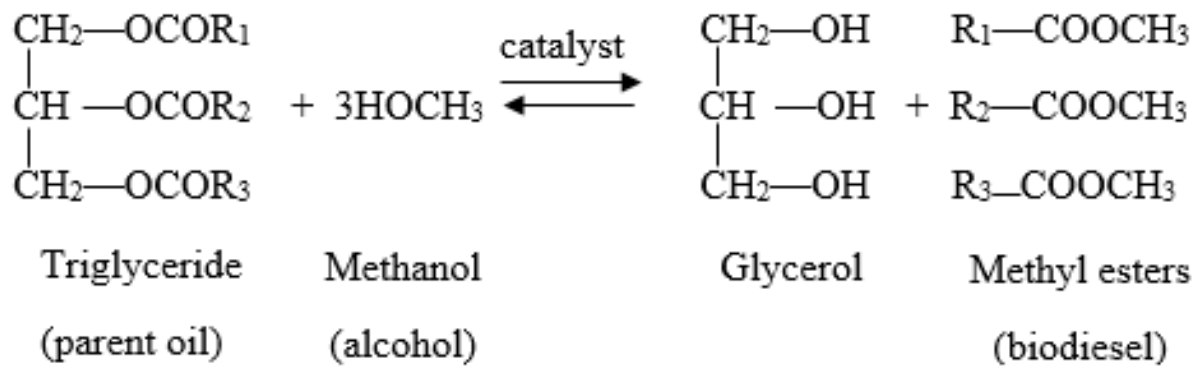

Fig 2. Algae biodiesel production using transesterification [54]

The efficiency of lipid production is related to overall lipid composition (i.e. percentage of dry cell weight [DCW] and biomass yield [daily dry mass growth $\left.\mathrm{L}^{-1}\right]$ ), which are the two crucial parameters to be considered for optimizing overall microalgae lipid yield [37]. Without these, reporting lipid content, the basic indicator both in terms of yield in unit volume and time, would be misleading. For example, a rapidly growing species might yield more lipids over a given period of time compared to a more lipid-containing species [55].

Because they contain a high fraction of PUFAs, microbial lipids have a large potential as a transportation fuel [56]; therefore, to realize higher economic performance, the lipid content in the microalgae must be higher [57]. Under stressful conditions, microalgae tend to accumulate more neutral lipids to protect themselves from photooxidation [58, 59]. These neutral lipids, especially TAGs, are used the most for biodiesel production [47].

Table 3. Parameters that affect lipid production in microalgae [37]

\begin{tabular}{|c|c|c|}
\hline Physicochemical Properties & Species-Dependent Factors & Culture System Improvement \\
\hline *Light & ${ }^{*}$ Lipid productivity & *Photosynthetic efficiency \\
\hline -Intensity & -Biomass productivity & -Light penetration \\
\hline -Spectral quality & -Lipid contents & -Light distribution \\
\hline *Temperature & *Fatty acid profiles & *Mass transfer rate \\
\hline -Reactive oxygen species level & -Optimal fatty acid ratio & -Aeration rate \\
\hline -Fatty acid composition & ${ }^{*}$ Harvesting method & *Nutrient control \\
\hline *Carbon dioxide (CO2) and pH & -Cell size & -Semipermeable membrane \\
\hline -CO2 concentration & -Cell density & \\
\hline - Bicarbonate ion (HCO3-) concentration & -Surface property & \\
\hline *Nutrient starvation & -Medium condition & \\
\hline -Nitrogen starvation & & \\
\hline (two-stage or continuous nitrogen limitation) & & \\
\hline
\end{tabular}

There are two main stress types-nutritional and physical-exerted on microalgae. Nutritional stresses include restrictions on nitrogen and phosphorus or an altered source of carbon. Physical stresses are related to the processing conditions, such as high light intensity, salinity, electromagnetic fields, metals, $\mathrm{CO}_{2}$ levels, and oxidative stresses [32, 60,61]. The key factors in lipid metabolism in microalgae that increase biodiesel yield are as follows: (1) stress can increase lipid content; (2) manipulation of the growth media can increase biomass yield; (3) some microalgae can survive marginal environmental conditions in which managing production and preventing contamination are easier; (4) lipid metabolism is completely known; and (5) some microalgae can also produce valuable chemicals, such as astaxanthin, lutein, and $\beta$-carotene [62].

Under specific conditions after inducing stresses and depending on the species, the lipid content in the microalgae can change to between 1 and $90 \%$ of their dry weight [6]. Table 3 lists the parameters to which changes can induce lipid accumulation. 
The cost of the microalgae-based biodiesel is comparable to that of petroleum diesel, and this has driven many researchers to study how to increase lipid production in microalgae to further decrease the cost of producing biodiesel [63-66]. Put simply, by following new methods by which high biomass yields, the desired lipid content, and the desired lipid composition can be generated, the overall efficiency of lipid production and other valuable chemicals produced by microalgae can increase $[16,43]$.

Because most microalgae accumulate a considerable amount of lipids under stress, lipid production can be highly efficient under specific conditions leading stresses. On the other hand, under these stress conditions in which lipids and TAGs are biosynthesized, cell growth and biomass yield are jeopardized, which also leads to protein decomposition and can affect the overall lipid yield differently depending on the species [36].

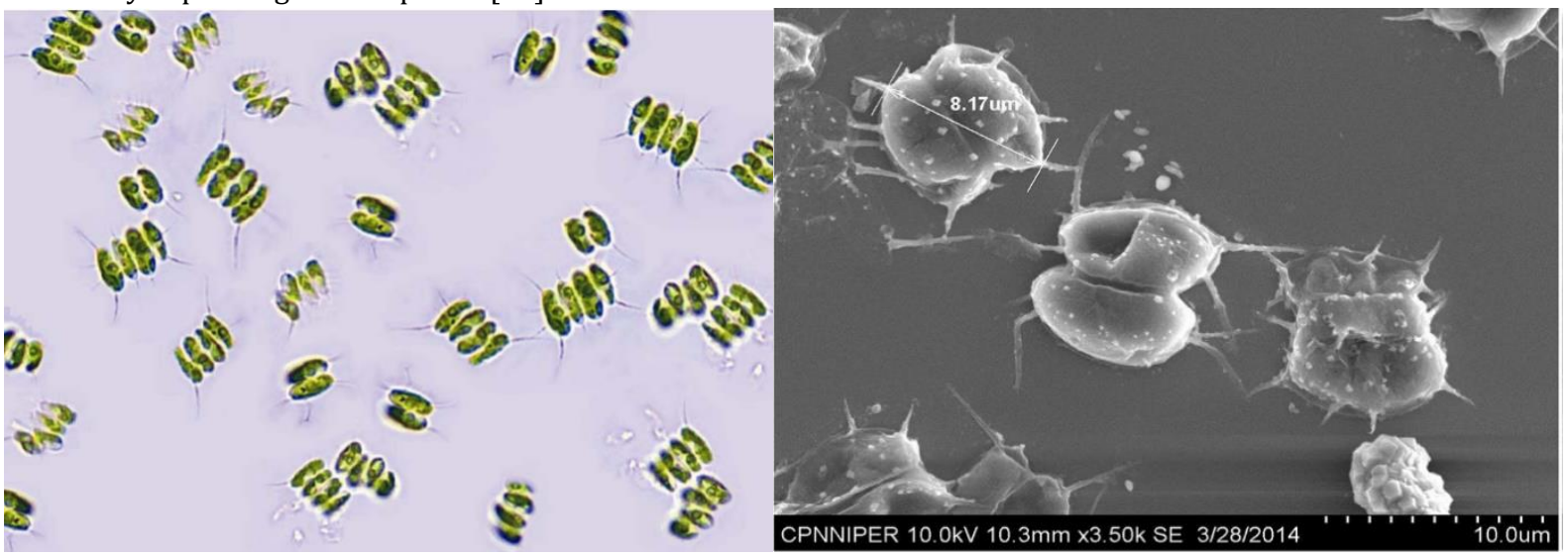

Fig 3. Scenedesmus sp. (a) Freshwater green microalgae Scenedesmus sp. ${ }^{1}$, (b) Scanning electron micrographs of S. quadricauda ${ }^{2}$ 1 [69]; ${ }^{2}[70]$

Different Scenedesmus species show differences in the number of cell spikes and the texture of their cell walls. Morphologic changes in Scenedesmus species result from changes in nutrient concentrations, $\mathrm{pH}$, and/or allelochemicals $[71,72]$.

\section{Nutrient stress}

Nitrogen, iron, phosphorus, magnesium, sulfur, and silicon are important for photosynthesis, cell division, respiration, intercellular transport, and protein synthesis in microalgae [73]. In particular, nitrogen and phosphorus are the two basic macronutrients for microalgae growth. Nitrogen is required for the synthesis of growth metabolites and protein, which are limiting factors on the overall growth rate, and is part of the chemical structure of nucleic acids, proteins, and other biomolecules [74]. Theoretically, these elements in the microalgae growth media should be within a stoichiometric ratio of $\mathrm{C}_{106} \mathrm{H}_{181} \mathrm{O}_{45} \mathrm{~N}_{16} \mathrm{P}$ for optimum growth ( $\mathrm{C}$ for carbon, $\mathrm{H}$ for hydrogen, $\mathrm{O}$ for oxygen, $\mathrm{N}$ for nitrogen, $\mathrm{P}$ for phosphorus). When the nitrogen: phosphorous ratio is $5: 1$, the environment is classified as nitrogen limiting, and when the ratio is $30: 1$, the environment is phosphorus limiting [43].

\section{General properties of Scenedesmus sp.}

The success of mass cultivation of microalgae, especially considering a low-value product, such as biodiesel, depends on selecting the correct species [55]. Even though there are many ways suggested in the literature by which to improve lipid production in microalgae, if the appropriate species is not used, several limitations can arise [37]. Nannochloropsis sp., Chlorella sp., Chlamydomonas sp., Scenedesmus sp., Dunaliella sp., Isochrysis sp., and Botryococcus braunii are multifunctional microalgae that accumulate lipids between 10 and $75 \%$ of their dry weights [21]. Among these, Scenedesmus sp. are considered to be the most appropriate microalgae for producing biodiesel because of their high biomass, lipid and carbohydrate yield and ability to grow in various wastewater environments, and short doubling time $[21,67,68]$. 
the desired product; however, doubling the biomass yield can reduce biodiesel prices by $41-42 \%$ [82]. Under nutrient-limiting conditions, microalgae relocate their carbon resources into energy-rich lipid and starch compounds [79]. The proportion of polar and nonpolar lipids can be controlled by changing the ratio of nitrogen, phosphorus, and inorganic carbon in the growth media [83].

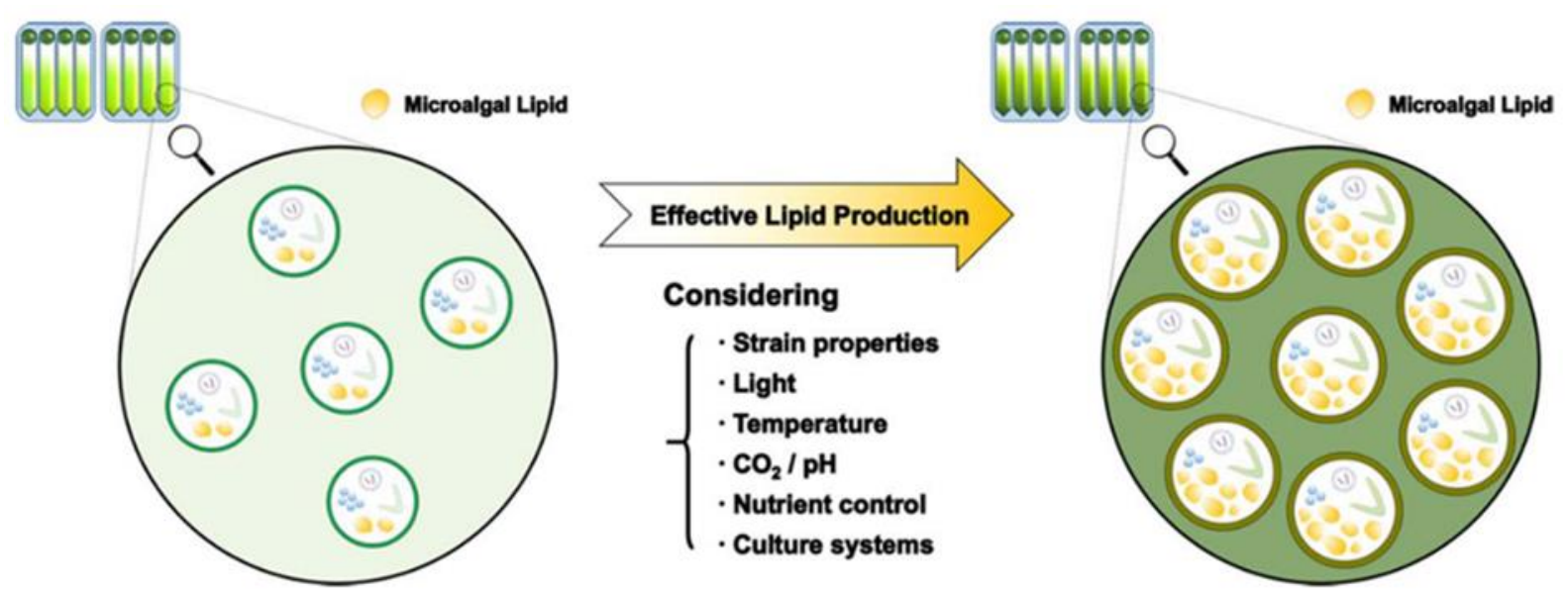

Fig 4. Effective lipid production in microalgae under various stress conditions [37]

There are three degrees of microalgae sensitivity to the manipulation of nutrient concentrationstarvation, limitation, and depletion. Khozin-Goldberg and Cohen [84] presented three possible reasons for lipid accumulation under nitrogen starved conditions: (1) decreased in cellular content of thylakoid membrane, (2) activation of acyl hydrolase and (3) stimulation of phospholipids hydrolysis $[78,85,86]$. Conventional process biochemistry approaches involving nutrient limitation/deprivation or physiological stress conditions might be useful for enhancing lipid content on dry weight basis. However, the increment in lipid content happens at the cost of biomass. So, it fails to enhance lipid productivity significantly. Therefore, the proportion of lipid productivity versus biomass formation remains same [78]. In Fig 5, the effects of physico-chemical parameters on lipid accumulations was given in a microalgal cell factory. As a nitrogen stress condition, nitrate starvation was defined in the algal cell. Other physico-chemical stress conditions also affect lipid accumulation in the algal cell but the probable mechanism for lipid accumulation is not known. Therefore, the knowledge of the biochemical mechanisms and molecular insights for lipid accumulation influenced by the environmental conditions might be improved by metabolic and molecular engineering.

During starvation, the microalgae are first grown in a nutrient-rich environment and then transferred into a nutrient-depleted environment. This nutrient deficiency results in the generation of high-energy compounds and their accumulation. In nutrientlimited media, one nutrient that limits maximum biomass production and induces a physiological reaction is limited while the others are abundant. The fundamental idea behind this condition is called "the law of the minimum", which assumes that there is usually one nutrient lacking in a media and that limits biomass growth while all other nutrients are in excess. This method is sequentially conducted in a culture medium. First, the cells are cultivated in a nutrient-rich environment and cell density and growth rate increase until the nutrients are depleted. Then, with changes in some metabolic processes, energy-rich compounds increase and growth rate and photosynthesis decrease [43].

\section{Nitrogen starvation}

Nitrogen is not only a significant element found in the structure of proteins and genetic material, but also one of the most prevalent elements in the entire structures, after carbon, hydrogen and oxygen; therefore, cells require nitrogen to grow and multiply [87]. Nitrogen deficiency in the microalgae growth media is applied as either nitrogen depletion or limitation (Fig 6). In nitrogen depletion, microalgae grow in a media without a nitrogen source; in nitrogen limitation, there is a specific nitrogen source but it is limited compared to that of other nutrients [88]. When nitrogen is limited more than other nutrients, photosynthesis will continue, but the chemicals produced in microalgae will have less nitrogen and be more energy rich (e.g., will contain more lipids and carbohydrates). Moreover, when the nitrogen in the cell is depleted, microalgae begin to decompose nitrogen-containing nonlipid cellular chemicals and free the nitrogen [89]. Nitrogen deficiency is the cheapest and easiest method by which to enhance lipid production; therefore, utilization of this method is widespread and is trustworthy and effective for many species [83]. 


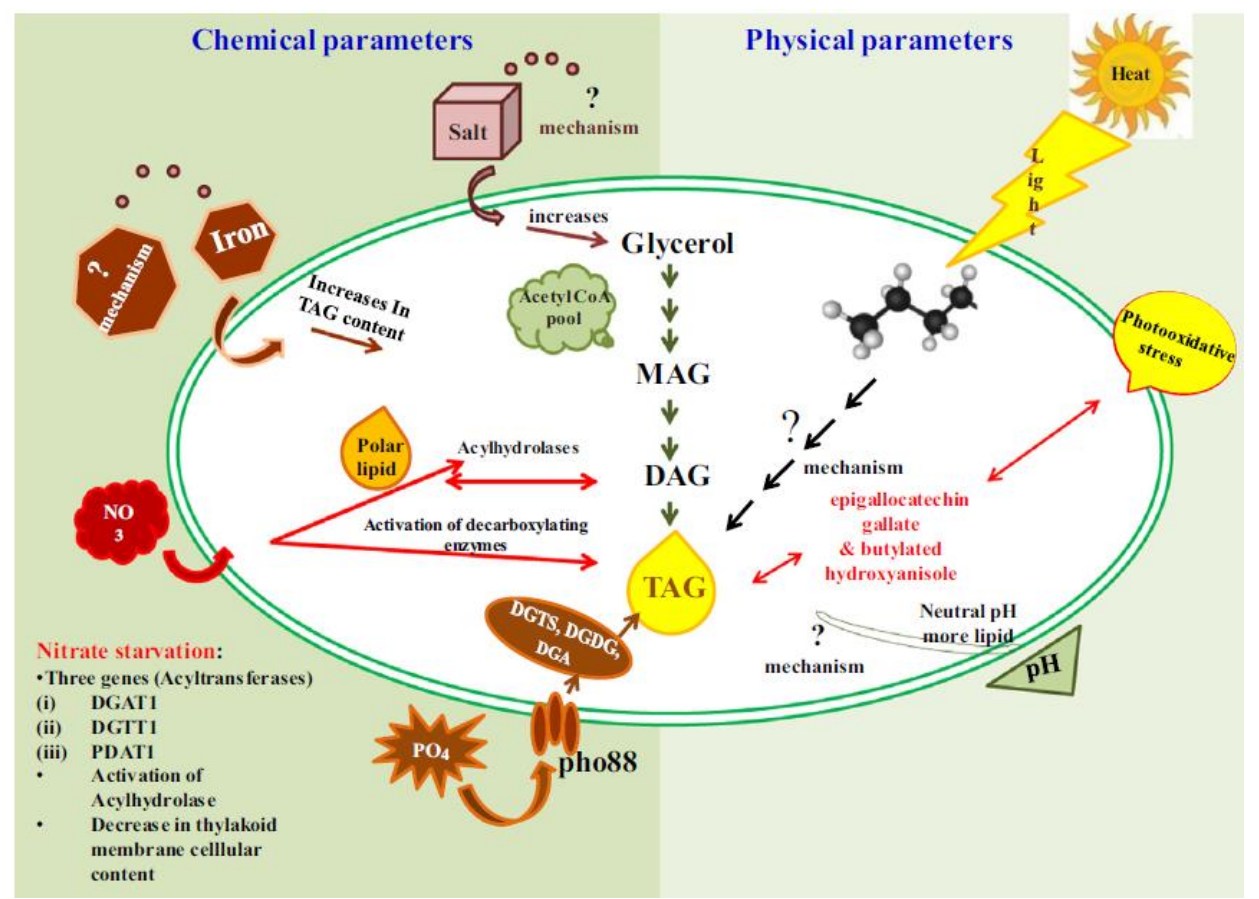

Fig 5. Description of physico-chemical parameters leading towards lipid accumulations in a microalgal cell factory. (Probable reasons for lipid accumulation: i) Nitrate starvation results in activation of acyltransferases, acylhydrolases and decrease in thylakoid membrane cellular content; (ii) Phosphate starvation results in storage lipid accumulation by activation of enzymes namely DGTS and DGDG and alteration in phosphate transporter may also lead to TAG synthesis; (iii) Increase in salt and iron content results in TAG formation but the exact mechanism is unknown) [78]

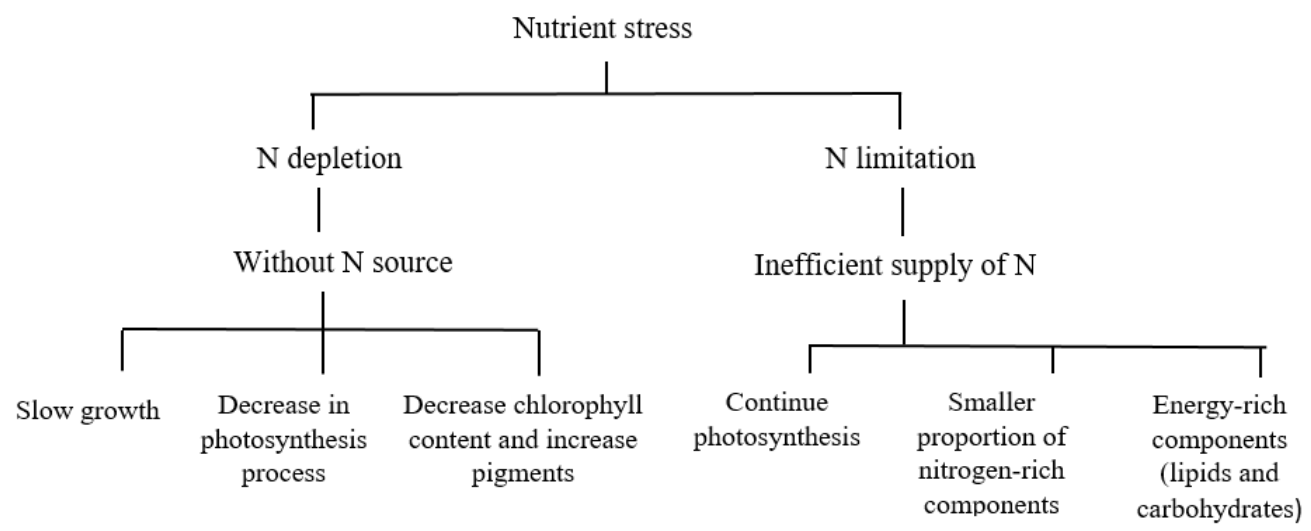

Fig 6. General overview of nitrogen stress in microalgae culture (Notes: N, nitrogen) [32]

Nitrogen is quantitatively important in growth media and its limitation, depending on the species, inhibits microalgae growth [90]. Declining cell multiplication changes the route through which lipids are synthesized from membrane lipids to neutral lipids [91].

Nitrogen limitation or starvation causes an increase in lipid and carbohydrate content while decreasing growth rate, protein synthesis, photosynthesis, and cell size [92]. Some examples for nitrogen starvation effect on lipid production of Scenedesmus sp. were shown in Table 4. Schnurr et al. [93] have researched the possibility of increasing the neutral lipid content in a nutrient-deficient algae biofilm using $S$. obliquus and Nitzschia palea. Although the neutral lipid content in suspensions of the same species was doubled, there was no concentration increase observed in their biofilms.

Many researchers have reported that nitrogen starvation decreases photosynthesis and protein synthesis but increases lipid and carbohydrate synthesis [92]. In addition, environmental conditions, especially nitrogen-rich nutrients, play a significant role in the amount and quality of the lipids produced in the microalgae $[47,93]$.

Lipid production in microalgae increases with nitrogen deficiency [95]-[96], and changes in the fatty acid chain length and unsaturation results in more suitable TAG production for biodiesel. Many microalgae species can similarly adapt their metabolism under nitrogen deficiency [47, 97]. During the stationary growth phase, nutrient starvation is the 
most well-known method by which to improve lipid content. In addition, temperature, salinity, light, and changes during the growth phase also impact microalgae metabolism [98]. Breuer et al. [99] have found that the highest lipid content, independent of light intensity, was observed in S. obliquus and changed from 18 to $40 \%$ of dry weight with changes in $\mathrm{pH}$ and temperature. This lipid accumulation stores the energy to be allocated for growth to prevent a decline in growth rate and, subsequently, in biomass and lipid production [100]. Toledo-Cervantes et al.
[101] have evaluated $\mathrm{CO}_{2}$, aeration, and light intensity impacts on the growth of and lipid production in S. obstusiusculus under nitrogen-limiting conditions. Without any nutrient limitations, in 20\% nonpolar algae-containing culture with $5 \% \mathrm{CO}_{2}$ and $134 \mu$ mole $\mathrm{m}^{-2} \mathrm{~s}^{-1}$ light intensity, biomass productivity was $500 \mathrm{~g}$ $\mathrm{m}^{-3} \mathrm{~d}^{-1}$ and maximum biomass concentration was $6000 \mathrm{~g} \mathrm{~m}^{-3}$. Under nitrogen-limiting conditions with $5 \% \mathrm{CO}_{2}$, lipid accumulation was $55.7 \%$ of the dry weight.

Table 4. Effect of nitrogen limitation/deprivation on lipid production of Scenedesmus sp.

$\begin{array}{lll}\text { Strain of Scenedesmus } s p . & \text { Lipid productivity } & \text { Refences }\end{array}$

\begin{tabular}{|c|c|c|}
\hline S. obliquus & $322 \mathrm{mg} \mathrm{L}^{-1} \mathrm{~d}^{-1}$ lipid productivity & [99] \\
\hline S. obstusiusculus & $\begin{array}{l}\text { For the inlet } \mathrm{CO} 2 \text { concentrations of } 0.04 \% \text { and } 5 \% \mathrm{CO} 2 \text {, the maximum } \\
\text { lipid productivities were } 51 \text { and } 200 \mathrm{~g} \mathrm{~m}^{-3} \mathrm{~d}^{-1} \text { respectively. }\end{array}$ & [101] \\
\hline S.obliquus $C N W-N$ & $45.48 \mathrm{mg} \mathrm{L}^{-1} \mathrm{~d}^{-1}$ lipid productivity & [103] \\
\hline S. acutus & $\begin{array}{l}\text { The amount of lipid in the } 50 \% \text { nitrogen-limited media was } 19.48 \% \\
\text { higher than that in the control group }\end{array}$ & [104] \\
\hline S. dimorphus & $0.17 \mathrm{~g} \mathrm{~L}^{-1} \mathrm{~d}^{-1}$ lipid productivity & [106] \\
\hline S. abundans & $5.999 \mathrm{~g} \mathrm{~L}^{-1} \mathrm{~d}^{-1}$ lipid productivity & [107] \\
\hline S. quadricauda & $25.13 \mathrm{mg} \mathrm{L}^{-1} \mathrm{~d}^{-1}$ lipid productivity & [108] \\
\hline S. obtusiusculus & $0.34 \mathrm{~g} \mathrm{~L}^{-1} \mathrm{~d}^{-1}$ lipid productivity & [109] \\
\hline Scenedesmus sp. LX1 & $204 \mathrm{mg} \mathrm{L}^{-1} \mathrm{~d}^{-1}$ lipid productivity & [85] \\
\hline
\end{tabular}

Although these nutrient-starvation conditions are generally considered for systems with long turnover periods, in recent studies, there have also been satisfactory results for systems with short-turnover periods [102]. The lipid content of Scenedesmus sp. changes with three different phases. The biomass on day 2 during the nitrogen-consuming logarithmic phase is dark green with $20 \%$ lipid content. During the early stress phase (5-7 d), the biomass is greenish yellow with $\sim 35 \%$ lipid content. During the late stress period (10-14 d), the biomass is brownish with $\sim 45 \%$ lipid content. Ho et al. [103] have applied nitrogen starvation to Scenedesmus obliquus and observed that the highest lipid content was $22.4 \%$ on day 5 . Agirman and Cetin [104] have investigated the development of Scenedesmus acutus and changes in its protein and lipid contents under nitrogen stress. According to their results, at $<50 \%$ nitrogen limitation, the lipid content was $19.48 \%$ higher than that of the control group. In addition, an inverse correlation was observed among cell development, lipid content, and nitrogen concentration.

Nitrogen starvation triggers several reactions in microalgae from the decomposition of nitrogencontaining compounds, such as proteins, chlorophyll, and DNA, to the accumulation of energy-rich compounds, such as carbohydrates [72]. The critical point here is that nitrogen-rich chlorophyll supports biomass growth and cellular development. Microalgae synthesize chlorophyll in huge amounts when nitrogen is plentiful and within their reach; however, when the opposite is true, they begin to use chlorophyll to obtain free nitrogen [101]. Because chlorophyll is green in microalgae, its decomposition results in microalgae becoming first greenish yellow and then brown when nearly all chlorophyll has been decomposed [32]. Wu et al. [105] have reported that in Scenedesmus sp., the concentration of nitrogen and phosphorus is highest during the exponential growth phase and lower during the stationary phase. Similarly, Wang et al. [106] have set up a 
photobioreactor that is open to the atmosphere, and under nitrogen starvation, observed that over a 10 -d period, the protein content in Scenedesmus $s p$. decreased from 33 to $10 \%$ and the total lipid content increased from 8 to $37 \%$.

\section{CONCLUSIONS}

Microalgae are promising candidates for replacing fossil fuels because of their rapid growth, uniquely highly efficient solar energy conversion, sustainability and renewability, high lipid content, and high potential for biofuel production. Microalgae use has been increasing as feedstock for biofuel in response to the energy crisis. In particular, the energy stores in microalgae are the raw materials for the biodiesel used in the transportation sector, and enhancement of microalgae's lipid content and its subsequent production have gained considerable attention among researchers. This review has illustrated that limiting nitrogen in the culture of high lipid-accumulating Scenedesmus sp. is a feasible strategy by which to increase lipid production.

\section{ACKNOWLEDGEMENT}

The author would like to thank The Scientific and Technological Research Council of Turkey (TUBITAK) Science Fellowships and Grant Programmes Department for the Post-Doctoral Research given to the author within "2219-Post-Doctoral PostFellowship Scholarship Program". Also, the author would like to thank Prof Bruce E. Rittmann and the laboratory group from the Arizona State UniversityThe Biodesign Institute Swette Center for Environmental Biotechnology, who granted the author with training in "Increasing Microalgae Productivity" in their research centers.

\section{REFERENCES}

[1]. R.A. Voloshin, M.V. Rodionova, S.K. Zharmukhamedov, T. Nejat Veziroglu, and S.I. Allakhverdiev, "Review: biofuel production from plant and algal biomass," International Journal of Hydrogen Energy, Vol. 41(39), pp. 17257-17273, 2016.

[2]. K.L. Man, and K.T. Lee, "Microalgae biofuels: a critical review of issues, problems and the way forward," Biotechnology Advances, Vol. 30(3), pp. 673-690, 2012.

[3]. D. Song, J. Fu, and D. Shi, "Exploitation of oilbearing microalgae for biodiesel," Chinese Journal of Biotechnology, Vol. 24(3), pp. 341-348, 2008.

[4]. M.K. Lam, and K.T. Lee, "Microalgae biofuels: a critical review of issues, problems and the way forward," Biotechnology Advances, Vol. 30(3), pp. 673-690, 2012.

[5]. Y. Chisti, "Biodiesel from microalgae beats bioethanol," Trends in Biotechnology, Vol. 26(3), pp. 126-131, 2008.
[6]. Y. Chisti, "Biodiesel from microalgae," Biotechnology Advances, Vol. 25(3), pp. 294-306, 2007.

[7]. A. Banerjee, R. Sharma, and Y. Chisti, "Botryococcus braunii: a renewable source of hydrocarbons and other chemicals," Critical Reviews in Biotechnology, Vol. 22(3), pp. 245279, 2002.

[8]. S.H. Ho, X. Ye, T. Hasunuma, J.S. Chang, and A. Kondo, "Perspectives on engineering strategies for improving biofuel production from microalgae - a critical review," Biotechnology Advances, Vol. 32(8), pp. 1448-1459, 2014.

[9]. V. Amanor-Boadu, P.H. Pfromm, and R. Nelson, "Economic feasibility of algal biodiesel under alternative public policies," Renewable Energy, Vol. 67, pp. 136-142, 2014.

[10]. C. Santander, P.A. Robles, L.A. Cisternas, and M. Rivas, "Technical-economic feasibility study of the installation of biodiesel from microalgae crops in the Atacama Desert of Chile," Fuel Processing Technology, Vol. 125, pp. 267-276, 2002.

[11]. H.S. Kwak, J.Y.H. Kim, H.M. Woo, E. Jin, B.K. Min, and S.J. Sim, "Synergistic effect of multiple stress conditions for improving microalgal lipid production," Algal Research, Vol. 19, pp. 215224, 2016.

[12]. B. Singh, A. Guldhe, I. Rawat, and F. Bux, "Towards a sustainable approach for development of biodiesel from plant and microalgae," Reneweble and Sustainable Energy Reviews, Vol. 29, pp. 216-245, 2014.

[13]. A.J. Klok, D.E. Martens, R.H. Wijffels, and P.P. Lamers, "Simultaneous growth and neutral lipid accumulation in microalgae," Bioresource Technology, Vol. 134, pp. 233-243, 2013.

[14]. W.H. Leong, J.W. Lim, M.K. Lam, Y. Uemura, Y.C. Ho, "Third generation biofuels: A nutritional perspective in enhancing microbial lipid production," Renewable and Sustainable Energy Reviews, Vol. 91, pp. 950-961, 2018.

[15]. P. Spolaore, C. Joannis-Cassan, E. Duran, and A. Isambert, "Commercial applications of microalgae," Journal of Bioscience and Bioengineering, Vol. 101(2), pp. 87-96, 2006.

[16]. G. Sibi, V. Shetty, and K. Mokashi, "Enhanced lipid productivity approaches in microalgae as an alternative for fossil fuels-A review," Journal of Energy Institute, Vol. 89(3), pp. 330-334, 2016.

[17]. R.R. Narala, S. Garg, K.K. Sharma, S.R. ThomasHall, M. Deme, Y. Li, and P.M. Schenk, "Comparison of microalgae cultivation in photobioreactor, open raceway pond, and a twostage hybrid system," Frontiers in Energy Research, Vol. 4(29), pp. 1-10, 2016.

[18]. L. Barsanti, P. Gualtieri, Algae: Anatomy, Biochemistry, and Biotechnology, CRC Press, United States, 2014.

[19]. C.C. Fu, T.C. Hung, J.Y. Chen, C.H. Su, and W.T. $\mathrm{Wu}$, "Hydrolysis of microalgae cell walls for production of reducing sugar and lipid 
extraction," Bioresource Technology, Vol. 101(22), pp. 8750-8754, 2010.

[20]. G. Petkov, and G. Garcia, "Which are fatty acids of the green alga Chlorella?" Biochemical Systematics and Ecology, Vol. 35(5), pp. 281285, 2007.

[21]. T.M. Mata, A.C. Melo, M. Simões, and N.S. Caetano, "Parametric study of a brewery effluent treatment by microalgae Scenedesmus obliquus," Bioresource Technology, Vol. 107, pp. 151-158, 2012.

[22]. C.J. Zhu, Y.K. Lee, and T.M. Chao, "Effects of temperature and growth phase on lipid and biochemical composition of Isochrysis galbana TK1," Journal of Applied Phycology, Vol. 9(5), pp. 451-457, 1997.

[23]. X. Wu, E.M. Joyce, and T.J. Mason, "The effects of ultrasound on cyanobacteria," Harmful Algae, Vol. 10(6), pp. 738-743, 2011.

[24]. V. Ördög, W.A. Stirk, P. Bálint, J. van Staden, and C. Lovász, "Changes in lipid, protein and pigment concentrations in nitrogen-stressed Chlorella minutissima cultures," Journal of Applied Phycology, Vol. 24(4), pp. 907-914, 2012.

[25]. K. Chojnacka, and F.J. Marquez-Rocha, "Kinetic and stoichiometric relationships of the energy and carbon metabolism in the culture of microalgae," Biotechnology, Vol. 3(1), pp. 21-34, 2004.

[26]. N. Rashid, M.S. Ur Rehman, M. Sadiq, T. Mahmood, and J.I. Han, "Current status, issues and developments in microalgae derived biodiesel production," Reneweble and Sustainable Energy Reviews, Vol. 40, pp. 760-78, 2014.

[27]. G.Q. Chen, and F. Chen, "Growing phototrophic cells without light," Biotechnology Letters, Vol. 28(9), pp. 607-616, 2006.

[28]. S. Bellou, M.N. Baeshen, A.M. Elazzazy, D. Aggeli, F. Sayegh, and G. Aggelis, "Microalgal lipids biochemistry and biotechnological perspectives," Biotechnology Advances, Vol. 32(8), pp. 1476-1493, 2014.

[29]. G.H. Huang, F. Chen, D. Wei, X.W. Zhang, and G. Chen, "Biodiesel production by microalgal biotechnology," Applied Energy, Vol. 87(1), pp. 38-46, 2010.

[30]. M. Chen, H. Tang, H. Ma, T.C. Holland, K.Y.S. Ng, and S.O. Salley, "Effect of nutrients on growth and lipid accumulation in the green algae Dunaliella tertiolecta," Bioresource Technology, Vol. 102(2), pp. 1649-1655, 2011.

[31]. Y. Liang, N. Sarkany, and Y. Cui, "Biomass and lipid productivities of Chlorella vulgaris under autotrophic, heterotrophic and mixotrophic growth conditions," Biotechnology Letters, Vol. 31(7), pp. 1043-1049, 2009.

[32]. J.R. Benavente-Valdés, C. Aguilar, J.C. ContrerasEsquivel, A. Méndez-Zavala, and J. Montañez, "Strategies to enhance the production of photosynthetic pigments and lipids in chlorophycae species," Biotechnology Reports, Vol. 10, pp. 117-125, 2016.
[33]. L. Zhu, Z. Wang, Q. Shu, J. Takala, E. Hiltunen, P. Feng, and Z. Yuan, "Nutrient removal and biodiesel production by integration of freshwater algae cultivation with piggery wastewater treatment," Water Research, Vol. 47(13), pp. 4294-4302, 2013.

[34]. Y. Ma, X. Gao, Q. Wang, and Y. Liu, "Biodiesels from microbial oils: Opportunity and challenges," Bioresource Technology, Vol. 263, pp. 631-641, 2018.

[35]. K. Singh, D. Kaloni, S. Gaur, S. Kushwaha, and G. Mathur, "Current research and perspectives on microalgae- derived biodiesel," Biofuels, DOI: 10.1080/17597269.2017.1278932, 2017.

[36]. B. Chen, C. Wan, M.A. Mehmood, J.S. Chang, and F. Bai, "Manipulating environmental stresses and stress tolerance of microalgae for enhanced production of lipids and value-added productsA review," Bioresource Technology, Vol. 244(Pt 2), pp. 1198-1206, 2017.

[37]. Y.S. Shin, H.I. Choi, J.W. Choi, J.S. Lee, Y.J. Sung, and S.J. Sim, "Multilateral approach on enhancing economic viability of lipid production from microalgae: A review," Bioresource Technology, Vol. 258, pp. 335-344, 2018.

[38]. P.G. Roessler, "Purification and characterization of acetyl-CoA carboxylase from the diatom Cyclotella cryptica," Plant Physiology, Vol. 92, pp. 73-78, 1990.

[39]. K. Tsukahara, and S. Sawayama, "Liquid Fuel Production using Microalgae," Journal of the Japan Petroleum Institute, Vol. 48(5), pp. 251259, 2005.

[40]. KEMA Inc, Algae-to-energy opportunities in Louisiana: a market potential report. (Louisiana Economic Development, 2009.

[41]. P.S. Nigam, and A. Singh, "Production of liquid biofuels from renewable resources," Progress in Energy and Combustion Science, Vol. 37(1), pp. 52-68, 2011.

[42]. M.K. Lam, and K.T. Lee, "Microalgae biofuels: a critical review of issues, problems and the way forward," Biotechnology Advances, Vol. 30(3), pp. 673-90, 2012.

[43]. B. Sajjadi, W.Y. Chen, A.A.A. Raman, and S. Ibrahim, "Microalgae lipid and biomass for biofuel production: A comprehensive review on lipid enhancement strategies and their effects on fatty acid composition," Renewable and Sustainable Energy Reviews, Vol. 97, pp. 200232, 2018.

[44]. P.J.I.B. Williams, and L.M.L. Laurens, "Microalgae as biodiesel \& biomass feedstocks: review and analysis of the biochemistry, energetics \& economics," Energy \& Environmental Science, Vol. 3(5), pp. 554-590, 2010.

[45]. A. Sukenik, Y. Yamaguchi, and A. Livne, "Alterations in lipid molecular species of the marine eustigma tophyte Nannochloropsis sp.," Journal of Phycology, Vol. 29(5), pp. 620-626, 1993.

[46]. C.M. Torres, S.D. Ríos, C. Torras, J. Salvadó, J.M. Mateo-Sanz, and L. Jiménez, "Microalgae- based 
biodiesel: a multicriteria analysis of the production process using realistic scenarios," Bioresource Technology, Vol. 147, pp. 7-16, 2013.

[47]. Q. Hu, M. Sommerfeld, E. Jarvis, M. Ghirardi, M. Posewitz, M. Seibert, and A. Darzins, "Microalgal triacylglycerols as feedstocks for biofuel production: perspectives and advances," The Plant Journal, Vol. 54(4), pp. 621-639, 2008.

[48]. M. Olofsson, T. Lamela, E. Nilsson, J.P. Bergé, V. del Pino, P. Uronen, and C. Legrand, "Seasonal variation of lipids and fatty acids of the microalgae nannochloropsis oculata grown in outdoor large-scale photobioreactors," Energies, Vol. 5(12), pp.1577-1592, 2012.

[49]. G. Soydemir, "Characterization and evaluation of lipids of microalgae grown in wastewater," D. Eng. thesis, Gebze Technical University, Istanbul, Turkey, Ap. 2016.

[50]. N. Moazami, A. Ashori, R. Ranjbar, M. Tangestani, R. Eghtesadi, and A.S. Nejad, "Large-scale biodiesel production using microalgae biomass of Nannochloropsis," Biomass Bioenergy, Vol. 39, pp. 449-453, 2012.

[51]. M. Çelikkol Türkmani, “Chlorella protothecoides mikroalg türünün yetiştirilmesinde baca gazının etkisi," M. Eng. thesis, Yıldız Technical University, Istanbul, Turkey, Feb. 2016.

[52]. Z. Wen, and M.B. Johnson, "Microalgae as a feedstock for biofuel production," Communications and Marketing, College of Agriculture and Life Sciences, Virginia Polytechnic Institute and State University, Publication 442-886, Blacksburg, VA; 2009.

[53]. S. Mishra, K. Anand, and P.S. Mehta, "Predicting the cetane number of biodiesel fuels from their fatty acid methyl ester composition," Energy Fuels, Vol. 30(12), pp. 10425-10434, 2016.

[54]. B. Kuepker, Commission E, editor. European renewable energy policy. Brussels: European Commission, p. 1-10, 2015.

[55]. M.J. Griffiths, and S.T.L. Harrison, "Lipid productivity as a key characteristic for choosing algal species for biodiesel production," Journal of Applied Phycology, Vol. 21(5), pp. 493-507, 2009.

[56]. B. Liam, and P. Owende, "Biofuels from microalgae. A review of technologies for production, processing, and extractions of biofuels and co-products," Renewable and Sustainable Energy Reviews, Vol. 14(2), pp. 557$577,2010$.

[57]. Q. Hu, C.W. Zhang, and M. Sommerfeld, "Biodiesel from Algae: Lessons Learned Over the Past 60 Years and Future Perspectives," Juneau, Alaska: Annual Meeting of the Phycological Society of America, Journal of Phsicology, Vol. 42(1), pp. 40-41, 2006.

[58]. Y. Jiang, T. Yoshida, and A. Quigg, "Photosynthetic performance, lipid production and biomass composition in response to nitrogen limitation in marine microalgae," Plant Physiology and Biochemistry, Vol. 54, pp. 70-77, 2012.
[59]. C. Adams, V. Godfrey, B. Wahlen, L. Seefeldt, and B. Bugbee, "Understanding precision nitrogen stress to optimize the growth and lipid content tradeoff in oleaginous green microalgae," Bioresource Technology, Vol. 131, pp. 188-194, 2013.

[60]. Z. Liu, G. Wang, and B. Zhou, "Effect of iron on growth and lipid accumulation in Chlorella vulgaris," Bioresource Technology, Vol. 99(11), pp. 4717-4722, 2008.

[61]. L. Wang, Y. Li, M. Sommerfeld, Q. Hu, "A flexible culture process for production of the green microalga Scenedesmus dimorphus rich in protein, carbohydrate or lipid," Bioresource Technology, Vol. 129, pp. 289-295, 2008.

[62]. E.B. D’Alessandro, and N.R. Antoniosi Filho, "Concepts and studies on lipid and pigments of microalgae: A review," Renewable and Sustainable Energy Reviews, Vol. 58, pp. 832-841, 2016.

[63]. E.W. Becker, Microalgae: Biotechnology and Microbiology. Cambridge University Press, 1994.

[64]. G. Zhao, J. Yu, F. Jiang, X. Zhang, and T.W. Tan, "The effect of different trophic modes on lipid accumulation of Scenedesmus quadricauda," Bioresource Technology, Vol. 114, pp. 466$471,2012$.

[65]. X. Li, H. Hu, K. Gan, and Y. Sun, "Effects of different nitrogen and phosphorus concentrations on the growth, nutrient uptake, and lipid accumulation of a freshwater microalga Scenedesmus sp.," Bioresource Technology, Vol. 101(14), pp. 5494-5500, 2010.

[66]. L.F. Rios, B.C. Klein, L.F. Luz, R.M. Filho, and M.R.W. Maciel, "Nitrogen starvation for lipid accumulation in the microalga species Desmodesmus sp.," Applied Biochemistry and Biotechnology, Vol. 175(1), pp. 469-476, 2014.

[67]. S.S. Ho, C.Y. Chen, and J.S. Chang, "Effect of light intensity and nitrogen starvation on $\mathrm{CO} 2$ fixation and lipid/carbohydrate production of an indigenous microalga Scenedesmus obliquus CNW-N," Bioresource Technology, Vol. 113, pp. 244-252, 2012.

[68]. Y. Li, D. Han, M. Sommerfeld, and Q. Hu, "Photosynthetic carbon partitioning and lipid production in the oleaginous microalga Pseudochlorococcum sp. (Chlorophyceae) under nitrogen-limited conditions," Bioresource Technology, Vol. 102(1), pp. 123-129, 2011.

[69]. T. Řezenka and M. Temina, "Natural Microbial UV Radiation Filters - Mycosporine-like Amino Acids," Folia Microbiology, Vol. 49(4), pp. 1-14, 2004.

[70]. R.S. Gour, A. Chawla, H. Singh, R.S. Chauhan, and A. Kant, "Characterization and Screening of Native Scenedesmus sp. Isolates Suitable for Biofuel Feedstock," PLoS ONE, 11(5): e0155321. doi:10.1371/journal.pone.0155321.

[71]. M. Lürling, "Effect of grazing-associated infochemicals on growth and morphological development in Scenedesmus acutus 
(chlorophyceae)," Journal of Phycology, Vol. 34, pp. 578-586, 1998.

[72]. I. Pancha, K. Chokshi, B. George, T. Ghosh, C. Paliwal, R. Maurya, and S. Mishra, "Nitrogen stress triggered biochemical and morphological changes in the microalgae Scenedesmus sp. CCNM 1077," Bioresource Technology, Vol. 156, pp. 146-154, 2014.

[73]. X. Zhang, S. Yan, R.D. Tyagi, R.Y. Surampalli, and J.R. Vale'ro, "Wastewater sludge as raw material for microbial oils production," Applied Energy, Vol. 135, pp. 192-201, 2014.

[74]. M.T. Madigan, J.M. Martinko, P.V. Dunlap, and D.P. Clark, Brock: Biology of Microorganisms. Pearson Benjamin Cummings Inc, 2009.

[75]. R. Yadavalli, R.S. Ramogapol, and C.S. Rao, "Lipid Accumilation Studies in Chlorella pyreniodosa Using Customized Photobioreactor-Effect of Nitrogen Source, Light Intensity and Mode of Operation," International Journal of Engineering Research and Application, Vol. 2(3), pp. 24462453, 2012.

[76]. H. Wu, and X. Miau, "Biodiesel quality and biochemical changes of microalgae Chlorella pyrenoidosa and Scenedesmus obliquus in response to nitrate levels," Bioresource Technology, Vol. 170, pp. 421-427, 2014.

[77]. N. Yu, L.T.J. Dieu, S. Harvey, and D.-Y. Lee, "Optimization of process configuration and strain selection for microalgae-based biodiesel production," Bioresource Technology, Vol. 193, pp. 25-34, 2015.

[78]. G.D. Bhowmick, L. Koduru, and R. Sen, "Metabolic pathway engineering towards enhancing microalgal lipid biosynthesis for biofuel application-A review," Renewable and Sustainable Energy Reviews, Vol. 50, pp. 12391253, 2015.

[79]. R. Praveenkumar, K. Shameera, G. Mahalakshmi, M.A. Akbarsha, and N. Thajuddin, "Influence of nutrient deprivations on lipid accumulation in a dominant indigenous microalga Chlorella sp., BUM11008: evaluation for biodiesel production," Biomass Bioenergy, Vol. 37 (Supplement C), pp. 60-66, 2012.

[80]. C. Adams, V. Godfrey, B. Wahlen, L. Seefeldt, and B. Bugbee, "Understanding precision nitrogen stress to optimize the growth and lipid content tradeoff in oleaginous green microalgae," Bioresource Technology, Vol. 131, pp. 188-194, 2013.

[81]. X. Li, H.Y. Hu, K. Gan, S. Ying-xue, "Effects of different nitrogen and phosphorus concentrations on the growth, nutrient uptake, and lipid accumulation of a freshwater microalgae Scenedesmus sp.," Bioresource Technology, Vol. 101(14), pp. 5494-5500, 2010.

[82]. S. Nagarajan, S.K. Chou, S. Cao, C. Wu, and Z. Zhou, "An updated comprehensive technoeconomic analysis of algae biodiesel," Bioresource Technology, Vol. 145, pp. 150-156, 2013.
[83]. L. Rodolfi, G.C. Zittelli, N. Bassi, G. Padovani, N. Biondi, G. Bonini, and M.R. Tredici, "Microalgae for Oil: Strain Selection, Induction of Lipid Synthesis and Outdoor Mass Cultivation in a Low-Cost Photobioreactor," Biotechnology and Bioengineering, Vol. 102(1), pp. 100-112, 2009.

[84]. I. Khozin-Goldberg and Z. Cohen, "The effect of phosphate starvationon the lipid and fatty acid composition of the fresh water eustigmatophyte Monodus subterraneus," Phytochemistry, Vol. 7, pp. 696-701, 2006.

[85]. L. Xin, H. Hon-ying, G. Ke, and S. Ying-xue, "Effects of different nitrogen and phosphorus concentrations on the growth, nutrient uptake, and lipid accumulation of a freshwater microalga Scenedesmus sp.," Bioresource Technology, Vol. 101, pp. 5494-5500, 2010.

[86]. S.K. Lenka, N. Carbonaro, R. Park, S.M. Miller, I. Thorpe, and Y. Li, "Current advances in molecular, biochemical, and computational modeling analysis of microalgal triacylglycerol biosynthesis," Biotechnology Advances, Vol. 34, pp. 1046-1063, 2016.

[87]. J. Vymazal, Algae and Element Cycling in Wetlands, Lewis Publishers, Boca Raton, FL, 1995 (689 pp.).

[88]. F. Bona, A. Capuzzo, M. Franchino, and M.E. Maffei, "Semicontinuous nitrogen limitation as convenient operation strategy to maximize fatty acid production in Neochloris oleoabundans," Algal Research, Vol. 5, pp. 1-6, 2014.

[89]. J. Sheehan, T. Dunahay, J. Benemann, and P. Roessler, A Look Back at the U.S. Department of Energy's Aquatic Species Program: Biodiesel from Algae. Close-Out report. National Renewable Energy Lab, Department of Energy, Golden, Colorado, U.S.A. Report number NREL/TP-580-24190, 1998.

[90]. M. Arumugam, A. Agarwal, C.A. Arya, and A. Ahmed, "Influence of nitrogen sources on biomass productivity of microalgae Scenedesmus bijugatus," Bioresource Technology, Vol. 131, pp. 246-249, 2013.

[91]. A. Converti, A.A. Casazza, E.Y. Ortiz, P. Perego, and M.D. Borghi, "Effect of temperature and nitrogen concentration on the growth and lipid content of Nannochloropsis oculata and Chlorella vulgaris for biodiesel production," Chemical Engineering and Processing, Vol. 48(6), pp. 1146-1151, 2009.

[92]. D. Simionata, M.A. Block, N.L. Rocca, J. Jouhet, E. Marechal, and G. Finazzi, "The Response of Nannochloropsis gaditana to Nitrogen Starvation Includes De Novo Biosynthesis of Triacylgylcerols, a Decrease of Chloroplast Galactolipids, and Reorganization of the Photosynthetic Apparatus," E.C Journal ASMorg, Vol. 12(5), pp. 665-676, 2013.

[93]. P.J. Schnurr, G.S. Espie, and D.G. Alleni "Algae biofilm growth and the potential to stimulate lipid accumulation through nutrient starvation" Bioresource Technology, Vol. 136, pp. 337-344, 2013. 
[94]. P.G. Roessler, "Environmental-control of glycerolipid metabolism in microalgaecommercial implications and future-research directions," Journal of Phycology, Vol. 26, pp. 393-399, 1990.

[95]. Y. Li, J. Mu, D. Chen, F. Han, H. Xu, F. Kong, F. Xie, and B. Feng, "Production of biomass and lipid by the microalgae Chlorella protothecoides with heterotrophic- $\mathrm{Cu}(\mathrm{II})$ stressed (HCuS) coupling cultivation," Bioresource Technology, Vol. 148, pp. 283-92, 2013.

[96]. G.Q. Chen, Y. Jiang, and F. Chen, "Salt-induced alterations in lipid composition of diatom Nitzschia Laevis (Bacillariophyceae) under heterotrophic culture condition(1)," Journal of Phycology, Vol. 44, pp. 1309-1314, 2008.

[97]. G. Breuer, P.P. Lamers, D.E. Martens, R.B. Draaisma, and R.H. Wijffels, "The impact of nitrogen starvation on the dynamics of triacylglycerol accumulation in nine microalgae strains," Bioresource Technology, Vol. 124, pp. 217-226, 2012

[98]. N.R. Boyle, and J.A. Morgan, "Flux balance analysis of pri- mary metabolism in Chlamydomonas reinhardtii," BMC Systems Biology, Vol. 3 (4), pp. 1-14, 2009.

[99]. G. Breuer, P.P. Lamers, D.E. Martens, R.B. Draaisma, and R.H. Wijffels, "Effect of light intensity, $\mathrm{pH}$, and temperature on triacylglycerol (TAG) accumulation induced by nitrogen starvation in Scenedesmus obliquus," Bioresource Technology, Vol. 143, pp. 1-9, 2013.

[100]. R.H. Wijffels, and M.J. Barbosa, "An outlook on microalgal biofuels," Science, Vol. 329(5993), pp. 796-799, 2010.

[101]. A. Toledo-Cervantes, M. Morales, E. Novelo, and S. Revah, "Carbon dioxide fixation and lipid storage by Scenedesmus obtusiusculus," Bioresource Technology, Vol. 130, pp. 652-658, 2013.

[102]. E. Eustance, S. Badvipour, J.T. Wray, and M.R. Sommerfeld, "Biomass productivity of two Scenedesmus strains cultivated semi- continuously in outdoor raceway ponds and flatpanel photobioreactors," Journal of Applied Phycology, Vol. 28, pp. 1471-1483, 2016.

[103]. S.H. Ho, C.Y. Chen, and J.S. Chang, "Effect of light intensity and nitrogen starvation $\mathrm{CO} 2$ fixation and lipid/carbonhydrate production of an indigenous microalgae Scenedesmus obliquus CNW-N," Bioresource Technology, Vol. 113, pp. 244-252, 2012.

[104]. N. Agirman, and A.K. Cetin, "Effect of nitrogen limitation on growth, total lipid accumulation and protein amount in Scenedesmus acutus as biofuel reactor candidate," Natural Science and Discovery, Vol. 3(3), pp. 33-38, 2017.

[105]. Y.H. Wu, Y. Yu, X. Li, H.Y. Hu, Z.F. Su, “Biomass production of a Scenedesmus sp. under phosphorous-starvation cultivation condition," Bioresource Technology, 112 (2012) 193-198.

[106]. L. Wang, Y. Li, M. Sommerfeld, and Q. Hu, "A flexible culture process for production of the green microalga Scenedesmus dimorphus rich in protein, carbohydrate or lipid," Bioresource Technology, Vol. 129, pp. 289-295, 2013.

[107]. M. P. Rai and S. Gupta, "Effect of media composition and sunlight supply on biomass, lipid content and FAME profile for quality biofuel production from Scenedesmus abundans," Energy Conversion and Management, Vol. 141, pp. 85-92, 2017.

[108]. J. Anand and M. Arumugam, "Enhanced lipid accumulation and biomass yield of Scenedesmus quadricauda under nitrogen starved condition," Bioresource Technology, Vol. 34, pp. 1046-1063, 2016.

[109]. J. Cabello, A. Toledo-Cervantes, L. Sánchez, S. Revah, and M. Morales, "Effect of the temperature, $\mathrm{pH}$ and irradiance on the photosynthetic activity by Scenedesmus obtusiusculus under nitrogen replete and deplete conditions," Bioresource Technology, Vol. 181, pp. 128-135, 2015. 